Música, teatro y cine: medios y funciones

\title{
La zarzuela costarricense
}

\author{
Roberto Le Franc Ureña \\ Investigador (Jubilado), Costa Rica \\ robertolefranc@gmail.com \\ https://orcid.org/0000-0002-3371-3635
}

Recibido: 19 de setiembre de 2019

Aceptado: 8 de noviembre de 2019

Resumen: La zarzuela es un género musical español que tuvo su origen en el siglo XVI. Se incluye dentro de las artes escénicas y básicamente se divide en zarzuela grande y en género chico. La época de su auge y esplendor fue en el siglo XIX.

En Costa Rica se conoce a partir de 1850. Posteriormente fueron recreadas por algunos compositores musicales nacionales ya que desde sus inicios tuvieron gran aceptación por ser obras escénico-musicales expresadas en idioma español.

Sin seguir estrictamente un criterio musicológico o técnico musical, este trabajo es más una recopilación de datos dispersos sobre los compositores nacionales que incursionaron en el campo de la zarzuela o de modestas obras escénicomusicales agrupadas como zarzuelas o como género chico, tan celebrado y gustado en España. Con lo anterior se quiso demostrar que en Costa Rica este género musical tuvo sus exponentes y que con muy buen tino dieron a los costarricenses lo mejor de su esfuerzo.

Palabras clave: zarzuela; zarzuela grande; género chico; obras escénico musical

\section{The Costa Rican zarzuela}

Abstract: The zarzuela is a Spanish musical genre that had its origin in the XVI century. It is included in the performing arts and is basically divided into large zarzuela and small gender. The time of its rise and splendor was in the nineteenth century.

\section{(C) $(\Theta \odot$}

La Revista Estudios es editada por la Universidad de Costa Rica y se distribuye bajo una Licencia Creative Commons Atribución-NoComercial-CompartirIgual 3.0 Costa Rica. Para más información envíe un mensaje a 
Revista Estudios, (39), 2019.

Diciembre 2019-Mayo 2020

ISSN 1659-3316

Le Franc Ureña Roberto

In Costa Rica it is known from 1850. Later they were recreated by some national musical composers since since its inception they had great acceptance for being stage-musical works expressed in Spanish.

Without strictly following a musicological or musical technical criterion, this work is more a collection of scattered data about national composers who dabbled in the field of zarzuela or modest scenic-musical works grouped as zarzuelas or as a small genre, so celebrated and liked in Spain. With the above it was wanted to demonstrate that in Costa Rica this musical genre had its exponents and that with very good tino they gave the Costa Ricans the best of their effort.

Keywords: zarzuela; big zarzuela; short gender; musical stage works

\section{I) INTRODUCCIÓN}

La zarzuela es un género musical surgido en España en el siglo XVII que se distingue por contener partes habladas, partes vocales (dúos coros, solos) y orquestales, que giran alrededor de una trama o argumento.

De una manera reductora y errónea algunos autores han querido comparar la zarzuela con la opereta, género de origen francés, principalmente por contener partes habladas o declamadas, pretendiendo así que "la zarzuela es la opereta española" lo cual es un error ya que la zarzuela es históricamente anterior a la opereta y sus características ya se encontraban en otros géneros musicales europeos, también anteriores a la opereta y no necesariamente anteriores a la zarzuela. La zarzuela podría ser tal vez el equivalente español de la "opéra comique" francés (1) o del "Singspiel" alemán (2).

Este arte lírico escénico poco tiempo después de su aparición se extendió a la casi totalidad de la península ibérica y por ende a las colonias del que fue el inmenso imperio español.

En nuestro país se fortaleció el gusto de los costarricenses principalmente a partir de la década de 1850 cuando empezaron "a llegar compañías líricas, ya fuera para la presentación de óperas o de zarzuelas" (Vargas, 2004, pp 89-90) y que se

\section{(C) $(00$}

La Revista Estudios es editada por la Universidad de Costa Rica y se distribuye bajo una Licencia Creative Commons Atribución-NoComercial-CompartirIgual 3.0 Costa Rica. Para más información envíe un mensaje a revistaestudios.eeg@ucr.ac.cr. 
Revista Estudios, (39), 2019.

Diciembre 2019-Mayo 2020

ISSN 1659-3316

Le Franc Ureña Roberto

llevaban a cabo en el Teatro Municipal, el antiguo Teatro Mora, posteriormente en

el Teatro Variedades y luego en el Teatro Nacional a partir de 1897.

\section{II) ¿QUÉ ES LA ZARZUELA?}

Por zarzuela entendemos aquella obra dramática, cómica o fantasiosa, originaria de España, en la que se alternan fragmentos hablados y cantados de acuerdo a un argumento o trama.

Los temas que en ella se tratan son variados y por lo general explotan situaciones regionales, fantásticas, de crítica social o bien aspectos de la vida real, novelescos - exóticos expresados en modismos, regionalismos, jerga popular o costumbrismos regionalistas, en escenas cómicas, dramáticas o de contenido amoroso.

El nombre genérico zarzuela puede derivarse,

“...del lugar y palacio o pabellón de caza del infante don Fernando (de Austria) situado en el Pardo, por la abundancia de zarzas y hierbas silvestres que había... y a que es el nombre conque se conoce a otros lugares castellanos.

Al marchar a Flandes el infante ... mandó ampliar el edificio para dar en él funciones de no mucho aparato que se conocieron con el nombre de "fiestas de la zarzuela..." (Peña y Goñi, 1967, p. 255).

Durante el reinado de Felipe IV, monarca gran amante del teatro y aficionado a los espectáculos musicales cargados de efectos, se celebraban representaciones nocturnas o fiestas cortesanas con música con el fin de aprovechar los momentos de descanso con sus cortesanos y para distraerse, contrataba compañías madrileñas que representaban obras en las que se alternaba el canto con pasajes hablados. Así nacieron las primeras zarzuelas como pequeños experimentos, un género musical que se situaba entre el teatro, el concierto, el sainete y la tonadilla (3).

Para algunos un género musical íntimo y sin importancia, para otros una de las mejores expresiones de la tradición musical española. De una u otra forma el género "zarzuela" hizo historia y trascendió las fronteras españolas y llegó a

\section{(c) (i) (2) (2)}

La Revista Estudios es editada por la Universidad de Costa Rica y se distribuye bajo una Licencia Creative Commons Atribución-NoComercial-CompartirIgual 3.0 Costa Rica. Para más información envíe un mensaje a revistaestudios.eeg@ucr.ac.cr. 
ISSN 1659-3316

Diciembre 2019-Mayo 2020

Le Franc Ureña Roberto

divulgarse y consolidarse con sus variaciones regionales, en otras latitudes del mundo hispano-parlante, en parte gracias a la acción de compañías líricas españolas que recorrían el mundo allá por los siglos XIX y XX.

En la actualidad, en la escena lírica española se debate sobre si existe o no una ópera española y si la zarzuela es representativa del género lírico hispano o si no lo es. Esta discusión queda para los entendidos, en nuestro caso se trata de tener una visión panorámica del desarrollo de zarzuela y cómo este género líricodramático-español influyó en algunos de nuestros compositores nacionales, principalmente hacia finales del siglo XIX y primeras décadas del siglo $\mathrm{XX}$, cayendo luego en desuso. Así fue necesario recopilar datos básicos sobre la zarzuela española, cuáles fueron algunos de sus mejores exponentes, así como, de sus principales obras.

En el caso de Costa Rica se consultó la obra de varios autores que recrearon el género de la zarzuela y se trató de conseguir la mayor información, desgraciadamente muy fragmentada y dispersa, sobre las obras compuestas por ellos. No se siguió para ello un criterio estrictamente técnico-musical o musicológico.

\section{III) DESARROLLO DE LA ZARZUELA}

Su génesis está muy probablemente allá por 1622 cuando se representa en la corte de Felipe IV la obra del conde de Villamediana "La Gloria de Niquea" con música atribuida a Palomares, a Juan Blas o a Ávaro según apuntan algunos autores (Peña y Goñi, 1967, p. 260).

Si bien en 1629 Lope de Vega (1562-1635) escribe una comedia con orquesta "La selva sin amor", no es sino hasta 1657 que Calderón de la Barca (1600-1681) usa el término "zarzuela" para su comedia "El golfo de las sirenas", término que luego cae en desuso.

\section{(c) (1)(2)}

La Revista Estudios es editada por la Universidad de Costa Rica y se distribuye bajo una Licencia Creative Commons Atribución-NoComercial-CompartirIgual 3.0 Costa Rica. Para más información envíe un mensaje a revistaestudios.eeg@ucr.ac.cr. 
Revista Estudios, (39), 2019.

Diciembre 2019-Mayo 2020

ISSN 1659-3316

Le Franc Ureña Roberto

Este nuevo estilo de teatro musical fue recreado también por Juan Hidalgo (16141685) y Juan Vélez de Guevara (1611-1675), quienes estrenan en 1672 “Los celos hacen estrellas".

Durante el transcurso del siglo XVIII este tipo de teatro musical se convierte poco a poco en obras estilísticamente parecidas a las óperas italianas, ejemplo de ello son algunas obras de Antonio de Literes (1673-1747) como "Los elementos" y "Jupiter y Semele".

Durante el reinado de Carlos III (1759-1788), luego de superar algunos problemas políticos en 1768 se retoma la tradición popular española representada ahora por los sainetes de Ramón de la Cruz (1731-1794), entre ellos "Las segadoras de Vallecas", con música de Rodríguez de Hita (1722-1787).

En el siglo XIX, a partir de 1839, la zarzuela se constituye como un género musical de importancia que dejó su huella en el desarrollo de la lírica española, ejemplo de ellos son las obras de Francisco Asenjo Barbieri (1823-1894), "Pan y Toros", "Jugar con fuego", "El Barberillo de Lavapies", entre otras o de Emilio Arrieta (1821-1894) con su inmortal "Marina", estrenada como ópera y luego como zarzuela.

Ya para esta época el género adquiere sus características propias, o sea obras escénico musicales con números hablados, cantados y coros que se mezclan en escenas cómicas, o de contenido amoroso, por lo general en dúos, que explotan el costumbrismo y regionalismo con presencia en los libretos de modismos, regionalismos o jerga popular.

Es a mediados del siglo XIX que el género zarzuela se divide en zarzuela grande (obras de dos, tres o más actos llamados Zarzuela Grande) y género chico (obras cortas de un acto denominadas también entremés sainete, juguete cómico lírico, humorada o revista musical) de acuerdo a los intereses de sus autores (Peña y Goñi, 1967).

\section{(c) (i) (2)}

La Revista Estudios es editada por la Universidad de Costa Rica y se distribuye bajo una Licencia Creative Commons Atribución-NoComercial-Compartirlgual 3.0 Costa Rica. Para más información envíe un mensaje a revistaestudios.eeg@ucr.ac.cr. 
a) La Zarzuela Grande

La zarzuela grande (entre paréntesis anotamos fecha estreno de la obra en referencia) sigue en un principio la moda italianizante en boga, ejemplos de ello son las obras de Francisco Asenjo Barbieri "Jugar con fuego" (1851); "Los diamantes de la corona" (1854); de Emilio Arrieta "Marina" (1855) y de Marcos Zapata "El anillo de hierro" (1878), moda que luego se abandona constituyéndose en obras de estilo nacionalista.

Así pues la Zarzuela Grande explota temas dramáticos, cómicos de acción complicada, casos de la vida real, fantásticos o exóticos y entre sus características están el contener números hablados, cantados o corales que se mezclan con escenas de contenido amoroso (en dúos y solos principalmente) dentro de un contexto que contempla temas del costumbrismo o regionalismo con la presencia de bailes regionales, parlamentos y libretos con modismos y elementos de la jerga popular, en obras más extensas de dos, tres o más actos.

Algunos ejemplos de este estilo puede ser los trabajos de Ruperto Chapí "La Tempestad" (1882); "La bruja" (1887); "El rey que rabió" (1891); de Jacinto Guerrero "Los gavilanes" (1923); de Reveriano Soutullo y Juan Vert "La leyenda del beso" (1924); "La del Soto del Parral" (1927); de Amadeo Vives "Doña Francisquita" (1923); de Manuel Penella "El gato montés“" (1917); "Don Gil de Alcalá" (1932) o de Federico Moreno Torroba "Luisa Fernanda" (1932).

Entre muchas más obras maravillosas que surgieron para el deleite de generaciones y que aún hoy día son llevadas a escena.

b) El género chico

La zarzuela chica o género chico (entre paréntesis, fechado, estreno de la obra en referencia), considerado un subgénero de la zarzuela grande, es de formato breve, por lo general en un acto, dividido en varios cuadros y que representa a menudo temas ligeros de corte popular. Su objetivo sería el puro entretenimiento y la

La Revista Estudios es editada por la Universidad de Costa Rica y se distribuye bajo una Licencia Creative Commons Atribución-NoComercial-CompartirIgual 3.0 Costa Rica. Para más información envíe un mensaje a revistaestudios.eeg@ucr.ac.cr. 
diversión del público, en contraposición a los temas más serios o dramáticos y de acción complicada de la zarzuela "mayor" o "grande", en él se simplifica todo para tratar temas más bien costumbristas, acerca de la vida cotidiana en Madrid, de talante disparatado y caricaturesco. Por ello tuvo tanto éxito entre el público, pues éste podía seguir fácilmente el argumento y sentirse identificado con los personajes de la obra que les reflejaba; pues en tiempos complicados tendía a buscar la evasión en el entretenimiento, lo que permitía no pensar en el "mundo exterior" (4).

Su nacimiento se sitúa en "EI Recreo" en 1867, un pequeño teatro de la madrileña calle la Flor. Este género fue promovido por empresarios y creado por un grupo de actores cómicos, Juan José Luján, Antonio Riquelme y José Valdés, para impulsar el teatro por horas en el que, en un mismo día, se representaban varias obras. La menor duración de éstas (menos de una hora) abarataba el coste de las localidades, llegando hasta las clases humildes que abarrotaron el teatro. Las recaudaciones aumentaron espectacularmente, así como la producción de obras. Este fue el nacimiento del "género chico" llamado así no por ser un teatro de menor calidad sino por ser más breve. En este tipo de teatro se refleja la vida cotidiana madrileña, mediante una música pegadiza y tarareable, hecha para servir al texto. Sus melodías van desde lo bailable, gracioso hasta lo sentimental y amoroso. Toda su música está basada en el folclor español: boleros, jotas, seguidillas, pasacalles, fandangos, habaneras, valses, mazurcas y por supuesto el chotis. El público aplaudió este nuevo tipo de teatro y se crearon tres nuevos recintos: el teatro Martín, el Lara y el Eslava...más tarde sus inventores se trasladarán del Recreo al teatro Variedades, situado en la calle Magdalena. En 1873 se inaugura el teatro Apolo, templo del "género chico". En un principio las representaciones eran sin música siendo "La canción de Lola" (libreto de Ricardo de la Vega, música de Chueca y Valverde) la primera obra que incorpora música (estrenada en 1880 en el teatro Alhambra en la calle Libertad" (5).

\section{(c) (i) (2)}

La Revista Estudios es editada por la Universidad de Costa Rica y se distribuye bajo una Licencia Creative Commons Atribución-NoComercial-CompartirIgual 3.0 Costa Rica. Para más información envíe un mensaje a 
Pertenecen a este género obras de autores muy reconocidos, entre ellos Federico Chueca con "Agua, azucarillos y aguardiente" (1897); Joaquín Valverde y Federico Chueca "Cádiz" (1886); Manuel Fernández Caballero "El dúo de la Africana" (1893); "Gigantes y cabezudos" (1898); Ruperto Chapí "El Tambor de Granaderos" (1896); Gerónimo Jiménez “La tempranica” (1900); así como los inmortales sainetes de Tomás Bretón "La verbena de la paloma" (1894); y de Ruperto Chapí "La revoltosa” (1897); entre tantas y tantas obras que dieron gloria a sus autores.

A finales del siglo XIX y comienzos del siglo XX se empieza a dar el apelativo de "género íntimo" referido a las representaciones conocidas como revistas y obras musicales con conexión a algunas ideas de la zarzuela, pero más ligeras y atrevidas, picarescas, con letra de doble intención como las obras de Vicente Lleó "La corte de Faraón" (1910) basada en la opereta francesa de León Xanrof "Madame Putiphar" (1897); de Francisco Alonso "Las Corsarias" (1919) o "Las leandras" (1931); o la muy famosa y archiconocida obra de Federico Chueca y Joaquín Valverde "La Gran Vía" (1886) estrenada en el Teatro Felipe de Madrid; obras muy censuradas desde su creación por sus alusiones picarescas de doble sentido o de orden político que ofendían a la moral y las buenas costumbres o aludían al poder político.

“La Gran Vía” fue una obra admirada por el gran Federico Nietzsche, que se refirió a ella considerándole como "genial, imposible de clasificar" (Valencia, 1962, p. 101).

En el siglo $X X$ se componen zarzuelas grandes consideradas de mejor o igual calidad musical que sus antecesoras como las ya citadas de Jacinto Guerrero, de Soutullo y Vert, de Amadeo Vives o de Manuel Penella, entre ellas podríamos incluir las zarzuelas de Pablo Zorozabal "La tabernera del Puerto" (1936), “Don Manolito" (1943), “Katiuska" (1931), y de Federico Moreno Torroba "Luisa Fernanda" (1932) o “La Chulapona” (1934), entre otras.

\section{(c) (i) (2)}

La Revista Estudios es editada por la Universidad de Costa Rica y se distribuye bajo una Licencia Creative Commons Atribución-NoComercial-CompartirIgual 3.0 Costa Rica. Para más información envíe un mensaje a revistaestudios.eeg@ucr.ac.cr. 
Como se anotó previamente es a partir de 1850- en que se empiezan a llegar al país compañías líricas de ópera y zarzuela. En 1868 la Compañía de Zarzuelas de Saturnino Blen presenta con gran éxito las obras "Catalina de Rusia" y "Los Maggiares" (Flores, 1978, p. 4) lo cual ayudó a fortalecer el gusto del público costarricense por este tipo de espectáculos: teatro hablado y cantado en español con música ligera y cantable.

En 1872 una compañía de zarzuelas (no se especifica el nombre) presenta el 28 de diciembre de ese año la zarzuela "El juramento", coadyuvando así con la llegada sistemática de diferentes compañías líricas que presentaron casi ininterrumpidamente una gran variedad de zarzuelas, sainetes o juguetes cómicos entre 1868 y 1915 (Fumero, 1994, p. 286).

Las primeras representaciones de zarzuela o de sainetes tuvieron lugar, sin lugar a dudas, en el Teatro Mora, inaugurado en 1850, posteriormente denominado Teatro Municipal y destruido por un terremoto en 1888. En este teatro actuaron agrupaciones extranjeras como la Compañía Luque, la Estudiantina Española, La Compañía Samaniego entre otras y aquí debutó la Compañía de Saturnino Blen con las obras ya mencionadas.

Con la inauguración del Teatro Variedades en 1891, el país contó con un importante centro de espectáculos y fue sede de las compañías líricas que nos visitaban, hasta la construcción del Teatro Nacional. Entre ellas podemos citar la Compañía Lírico Dramática de Saturnino Blen, La Infantil Mexicana de Zarzuelas, La López Ochoa y Alba, LA Compañía Palau, La Antonelli, La Valero, La Santagosa, La Dalman-Ughetti, La Catalá, La Peyres, La Bracale, ... sin dejar de lado la Compañía Dramática de Aficionados, grupo nacional que presentó por su cuenta algunas zarzuelas y que sirvió de apoyo a muchas de las compañías extranjeras (Fumero, 1994, p. 286).

\section{(c) (i) (9) (2)}

La Revista Estudios es editada por la Universidad de Costa Rica y se distribuye bajo una Licencia Creative Commons Atribución-NoComercial-CompartirIgual 3.0 Costa Rica. Para más información envíe un mensaje a 
En el Teatro Variedades subieron a escena y se dieron a conocer zarzuelas famosas, entre ellas "El anillo de hierro" de Marcos Zapata; "Los diamantes de la corona" de Francisco Asenjo Barbieri, "Marina" de Emilio Arrieta; "El rey que rabió" de Ruperto Chapí; "Cádiz" de Federico Chueca y Joaquín Valverde, entre muchas otras y en este teatro debutó nuestro gran tenor Manuel "Melico" Salazar.

Al inaugurarse el Teatro Nacional en 1897, mucha de la actividad teatral pasó a este recinto, quedando relegado a un segundo plano el Teatro Variedades, "El Cucarachero" como cariñosamente se le conoció. Luego se convirtió en un cinematógrafo con gran éxito, subsistiendo hasta nuestros días en el centro de San José y que será la futura sede de la Cinemateca Nacional.

En el Teatro Nacional se presentaron los principales conjuntos, compañías de ópera, de opereta, de zarzuela, solistas de fama internacional, compañías de drama, de comedia, estrellas del ballet clásico, de la danza y un sinnúmero de artistas de fama que deleitaron al público costarricense con sus actuaciones y contribuyeron a que éste fuera más crítico en sus apreciaciones. Quedaron atrás las épocas del Teatro Mora, del Municipal y del Variedades.

\section{V) LA ZARZUELA COSTARRICENSE}

Podríamos decir que a partir de 1850 el público costarricense se interesó y desarrolló un gusto especial por las representaciones teatrales, siendo la zarzuela una de las preferidas por combinar canto, teatro y baile en una trama no muy complicada.

A finales del siglo XIX la presentación de estas obras se efectuaba principalmente en los teatros Variedades y Nacional y fueron aliciente para que músicos nacionales incursionaran en el campo de la composición de zarzuelas; algunas de ellas tuvieron bastante éxito, otras fueron relegadas al olvido, se extraviaron o quedaron en archivos en espera de ser redescubiertas; otras nunca subieron a

\section{(C) $(00$}

La Revista Estudios es editada por la Universidad de Costa Rica y se distribuye bajo una Licencia Creative Commons Atribución-NoComercial-CompartirIgual 3.0 Costa Rica. Para más información envíe un mensaje a 
escena y de ellas únicamente su nombre se conserva. La mayoría de ellas se ubica dentro del llamado "género chico".

En todo caso, tenemos noticia que la primera obra de carácter nacional que se presentó en 1889 (desconocemos el sitio) fue, "Los dos huérfanos" zarzuela de Mateo Fournier Hetch (1851-1917) autor de su letra y música junto con su padre, ambos oriundos de Puerto Rico.

En orden de importancia seguía el juguete cómico lírico en un acto "Los pretendientes" con letra y música de Carlos Gagini Chavarría (1865-1925) y música del puertorriqueño Eduardo Cuevas Morales (¿-1912), compuesta en 1900 y representada en San José, tal vez en el Teatro Variedades único sitio que reunía las condiciones para este tipo de representaciones en esta época.

Merece especial atención por ser considerada una zarzuela grande la obra "EI marqués de Talamanca", con letra de Carlos Gagini Chavarría (1865-1925) y música del puertorriqueño Eduardo Cuevas Morales (¿-1912), zarzuela en tres actos que se estrenó en el Teatro Nacional el 24 de noviembre de 1900 y a cargo de la Compañía Dramática de Aficionados (Fumero, 1994, p.308).

La zarzuela en un acto "Espíritu de contradicción", con música de Octavio Morales Fernández(1863-1949) y con letra de Eduardo Calsamiglia Arias (1881-1918) se estrenó en el Palacio Municipal de Heredia el 12 de marzo de 1905 con mucho éxito y buenas reseñas y crítica de la prensa nacional; subiría a escena en San José para la reinauguracíon del Teatro Variedades, lo cual nunca sucedería porque se presentó otra obra "Fedora", con la Compañía Martínez Casado. El original de esta zarzuela lo llevó para su impresión en 1918 el señor Eduardo Calsamiglia, a la ciudad de Guatemala, desgraciadamente este falleció en ese país víctima de una epidemia de influenza y sus efectos personales junto al original de la obra fueron incinerados para evitar el contagio, de acuerdo a las medidas tomadas por el gobierno de ese país (Le Franc, 2009, p. 75).

En 1911 se estrenó la zarzuela "El pobre manco" de Gonzalo Sánchez Bonilla (1889- ¿?), desafortunadamente no existen más datos de esta obra. También se 

estrenó en ese año "Doña Restituta", zarzuela con letra de Eduardo Casalmiglia Arias (1881-1918) y música de Barrafón o Barragón (¿). No hay más datos de esta zarzuela. En 1913 se estrenó en Cartago la zarzuela cómica "El gamonal de la Cruz", con música de Luis Valle Martínez (1885-1968) y letra de Ernesto Ortega (¿), desconocemos el sitio donde se presentó, únicamente sabemos que las entradas se pusieron a la venta en el Salón París de esa ciudad.

Corría el año 1916 cuando Gonzalo Sánchez Bonilla (1889-¿) estrenó la zarzuela "La bachillera" en un teatro que fue construido por un grupo de admiradores de la controversial danzarina española "La Vidal". Esta artista se había presentado en el Teatro Variedades y había originado el retiro de algunas damas josefinas que repudiaron la presentación de la artista en traje "demasiado ligero". El teatro se fundó el 12 de agosto de 1911 con el nombre de Teatro Olympia y el género de obras que ahí se presentaban era "picante" pero no inmoral". Tal vez la zarzuela “La bachillera" seguía estos lineamientos. El teatro cambió su nombre por el de Teatro Moderno donde se presentaban obras picantes, un poco eróticas así como varietés. Posteriormente se convirtió en cinematógrafo y así perduró hasta su demolición. Se ubicaba 150 metros al sur del Parque Central de San José.

Julio Mata Oreamuno (1899-1969) estrenó en el Teatro Nacional la noche del 3 de noviembre de 1938, su zarzuela ambientada en Cartago, la capital colonial de Costa Rica, "Toyupán”. La obra en dos actos y un cuadro narra los amores de Toyupán con Dolores hija del Gobernador. La zarzuela tuvo gran éxito pero fue pocas veces representada; la última vez fue la noche de jueves 4 de julio de 2013 en una versión concierto de la Orquesta Sinfónica de la Universidad de Costa Rica y el Taller de Ópera EAM (Escuela de Artes Musicales). Una grabación hecha ese día por la Radio UCR se presenta ocasionalmente en el programa dominical de zarzuelas y operetas de esa radiodifusora.

Alcides Prado Quesada (1900-1984) estrenó el viernes 3 de junio de 1937 en el Teatro Raventós la zarzuela en tres actos con letra de su esposa Carmen Carvajal 
Martínez (1906-1949) "La casa del diablo", con Manuel Salazar Zúñiga "Melico" (1887-1950) en el papel de don José y María José (Pepita) Rodríguez (sf) como Sarita, entre muchos más. Esta zarzuela fue posteriormente reformada y rebautizada con el nombre de "Nuestra tierra" reestrenada con gran éxito el 19 de noviembre de 1948 en el Teatro Nacional.

Algunos años después, Prado estrena el 26 de julio de 1955 la zarzuela "Milagro de amor", con música de su autoría y letra de su esposa Carmen Carvajal. Esta zarzuela con música muy agradable fue representada en el Teatro Nacional en múltiples ocasiones con gran éxito de público y de taquilla. De ella existe una versión fílmica a colores que pertenece a la familia Prado. La zarzuela retrata con gran fidelidad algunas de las costumbres y tradiciones propias del medio rural costarricense, fue muy elogiada por la crítica de entonces.

Con Milagro de Amor se cierra un ciclo de composición de zarzuelas nacionales ya que a partir de 1955 nuestros compositores abandonan el interés por este género musical para orientar sus esfuerzos y componer obras de otros géneros como música de cámara, conciertos, canciones para voz y piano y obras orquestales, más de acuerdo al mundo moderno y tecnológico que incipientemente se desarrollaba en Costa Rica.

El cuadro resumen que seguidamente se presenta pretende complementar lo anteriormente expuesto y nos permite apreciar además el desempeño de otros compositores nacionales que incursionaron en el campo de la zarzuela así como en el campo de la opereta, la ópera o la comedia musical. En algunos casos no se pudo conseguir mayor información de algunas de ellas. 
Revista Estudios, (39), 2019.

ISSN 1659-3316

Diciembre 2019-Mayo 2020

Le Franc Ureña Roberto

\begin{tabular}{|c|c|c|c|c|}
\hline $\begin{array}{l}\text { COMPOSITOR } \\
\text { (AUTOR MÚSICA) }\end{array}$ & OBRA & GÉNERO & TEXTO & $\begin{array}{l}\text { FECHA Y LUGAR } \\
\text { DE ESTRENO }\end{array}$ \\
\hline $\begin{array}{l}\text { Enrique Jiménez } \\
\text { Núñez (1863-1932) }\end{array}$ & $\begin{array}{l}\text { Ensueños de } \\
\text { nochebuena }\end{array}$ & $\begin{array}{l}\text { Obra escénico } \\
\text { infantil }\end{array}$ & $\begin{array}{l}\text { María Isabel } \\
\text { Carvajal (Carmen } \\
\text { Lyra) (1887-1949) } \\
\text { y Rubén Coto (s.f.) }\end{array}$ & $\begin{array}{l}24 \text { de noviembre de } \\
1919 \quad \text { Escuela } \\
\text { Normal de Heredia }\end{array}$ \\
\hline $\begin{array}{ll}\text { Eduardo } & \text { Cuevas } \\
\text { Morales } & (i-1912) \\
\text { Puertorriqueño }\end{array}$ & Vindicta & Zarzuela & $\begin{array}{l}\text { Eduardo } \\
\text { Calsamiglia Arias } \\
(1881-1918)\end{array}$ & ¿? \\
\hline $\begin{array}{l}\text { César Nieto Casabo } \\
(1892-1969)\end{array}$ & $\begin{array}{l}\text { El caballero del guante } \\
\text { gris }\end{array}$ & Zarzuela & ¿? & ¿? \\
\hline Jenaro Valverde (s.f.) & El pollo tejada & Zarzuela & ¿? & $\begin{array}{l}\text { Se conserva } \\
\text { únicamente un folio } \\
\text { manuscrito, particella } \\
\text { para violín "La } \\
\text { paraguaya" } \\
\text { Archivo Histórico } \\
\text { Musical UCR }\end{array}$ \\
\hline ¿? & Flor del alma & Zarzuela & ¿? & $\begin{array}{l}\text { Estrenada en } 1917 . \\
\text { La cantó la soprano } \\
\text { Zelmira Segreda } \\
\text { Solera (1878-1923) }\end{array}$ \\
\hline $\begin{array}{l}\text { Pilar Jiménez Solís } \\
(1835-1922)\end{array}$ & Amor al trabajo & Zarzuela & $\begin{array}{l}\text { Adolfo } \quad \text { Romero } \\
\text { (s.f.) }\end{array}$ & Teatro Municipal \\
\hline $\begin{array}{l}\text { Pilar Jiménez Solís } \\
(1835-1922)\end{array}$ & $\begin{array}{l}\text { Gracias a Dios que } \\
\text { está puesta la mesa }\end{array}$ & $\begin{array}{l}\text { Zarzuela } \\
\text { atribuida a } \\
\text { Pilar Jiménez }\end{array}$ & ¿? & $\begin{array}{lr}\text { Teatro } & \text { Municipal. } \\
\text { Nota: } & \text { Francisco } \\
\text { Asenjo } & \text { Barbieri } \\
(1826-1894) & \text { tiene } \\
\text { una } & \text { zarzuela } \\
\text { estrenada en } & \text { Madrid } \\
\text { en 1852 con el } \\
\text { mismo nombre } \\
\text { (Peña y Coñi, } \\
\text { Antonio:1967:145) }\end{array}$ \\
\hline Manuel Antonio "Toño" & Refugiados & Zarzuela & Luis P. Alomar & ¿? \\
\hline
\end{tabular}

\section{(c) (i) (2)}

La Revista Estudios es editada por la Universidad de Costa Rica y se distribuye bajo una Licencia Creative Commons Atribución-NoComercial-CompartirIgual 3.0 Costa Rica. Para más información envíe un mensaje a revistaestudios.eeg@ucr.ac.cr. 
Revista Estudios, (39), 2019.

ISSN 1659-3316

Diciembre 2019-Mayo 2020 Le Franc Ureña Roberto

\begin{tabular}{|c|c|c|c|c|}
\hline Argüello (s.f.) & & & (s.f.) & \\
\hline $\begin{array}{l}\text { Alcides Prado } \\
\text { Quesada (1900-1984) }\end{array}$ & Caperucita roja & Zarzuela & $\begin{array}{lr}\text { Carmen } & \text { Carvajal } \\
\text { Martínez } & \text { (1906- } \\
1949) & \end{array}$ & ¿? \\
\hline $\begin{array}{l}\text { Julio } \quad \text { Fonseca } \\
\text { Gutiérrez (1881-1950) }\end{array}$ & Caperucita encarnada & $\begin{array}{l}\text { Dramatización } \\
\text { infantil }\end{array}$ & $\begin{array}{l}\text { María Isabel } \\
\text { Carvajal } \\
\text { Lyra) (Carmen } \\
\text { (1887-1949) }\end{array}$ & $\begin{array}{l}1939 \text { Escuela } \\
\text { República del Perú. } \\
\text { San José }\end{array}$ \\
\hline Jaime Galvez (s.f.) & Tabare & Zarzuela & ¿? & $\begin{array}{ll}1943 & \text { Teatro } \\
\text { Nacional } & \end{array}$ \\
\hline $\begin{array}{l}\text { Wílber Alpírez } \\
\text { Quesada (1931-2017) }\end{array}$ & Garabito & $\begin{array}{l}\text { Zarzuela en } \\
\text { tres actos }\end{array}$ & $\begin{array}{l}\text { Moisés Alpírez } \\
\text { Garay (1901-1993) }\end{array}$ & $\begin{array}{ll}\text { Nunca } & \text { fue } \\
\text { representada (6) } & \end{array}$ \\
\hline $\begin{array}{l}\text { Julio } \quad \text { Fonseca } \\
\text { Gutiérrez (1881-1950) }\end{array}$ & El dinero no es todo & Opereta & ¿? & Obra extraviada \\
\hline $\begin{array}{l}\text { Alcides Prado } \\
\text { Quesada (1900-1984) }\end{array}$ & Aladino & Opereta & $\begin{array}{lr}\text { Carmen } & \text { Carvajal } \\
\text { Martínez } & \text { (1906- } \\
1949) & \end{array}$ & $\begin{array}{l}10 \text { de mayo } 1953 \\
\text { Teatro Nacional }\end{array}$ \\
\hline $\begin{array}{l}\text { Wílber Alpírez } \\
\text { Quesada (1931-2017) }\end{array}$ & El príncipe amor & Opereta & $\begin{array}{l}\text { Moisés Alpírez } \\
\text { Garay (1901-1993) }\end{array}$ & $\begin{array}{l}\text { Nunca representada } \\
\text { (6) }\end{array}$ \\
\hline $\begin{array}{ll}\text { Dolores Castegnaro } \\
\text { Catellanni }\end{array}$ & Mirka & Opereta & ¿? & ¿? \\
\hline Jaime Gálvez & Sueños de reina & Opereta & Jaime Gálvez & $\begin{array}{l}7 \text { de febrero } 1937 \\
\text { Teatro Nacional }\end{array}$ \\
\hline $\begin{array}{l}\text { Julio Mata Oreamuno } \\
(1899-1969)\end{array}$ & Rosas de Norgaria & Opereta & $\begin{array}{l}\text { Carlos Orozco } \\
\text { Castro (s.f.) }\end{array}$ & $\begin{array}{l}27 \text { de julio } 1937 \\
\text { Teatro Nacional }\end{array}$ \\
\hline $\begin{array}{l}\text { Benjamín Gutiérrez } \\
\text { Sáenz (1937) }\end{array}$ & $\begin{array}{l}\text {-El pájaro del } \\
\text { crepúsculo } \\
\text {-Marianela } \\
\text {-El regalo de los reyes }\end{array}$ & Ópera & $\begin{array}{l}\text { Benjamín Gutiérrez } \\
\text { Sáenz } \\
\text { Benjamín Gutiérrez } \\
\text { Sáenz } \\
\text { O. Henry (s.f.) }\end{array}$ & $\begin{array}{l}1960 \\
i \\
i\end{array}$ \\
\hline Alcides & María & Ópera & Carmen Carvajal & 1976 \\
\hline
\end{tabular}

La Revista Estudios es editada por la Universidad de Costa Rica y se distribuye bajo una Licencia Creative Commons Atribución-NoComercial-CompartirIgual 3.0 Costa Rica. Para más información envíe un mensaje a revistaestudios.eeg@ucr.ac.cr. 
Revista Estudios, (39), 2019.

ISSN 1659-3316

Diciembre 2019-Mayo 2020

\begin{tabular}{|c|c|c|c|c|}
\hline Quesada (1900-1984) & & & $\begin{array}{l}\text { Martínez } \\
\text { 1949) }\end{array}$ & \\
\hline $\begin{array}{lll}\text { Bernal } & \text { Flores } & \text { Zeller } \\
(1937) & & \end{array}$ & $\begin{array}{l}\text { The Land of Heart's } \\
\text { Desire }\end{array}$ & $\begin{array}{l}\text { Ópera atonal } \\
\text { Tesis Doctoral }\end{array}$ & $\begin{array}{l}\text { Texto en inglés del } \\
\text { autor }\end{array}$ & $\begin{array}{l}1964 \text { Rochester, } \\
\text { New York }\end{array}$ \\
\hline $\begin{array}{l}\text { Daube } \quad \text { Barquero } \\
\text { Sánchez }(1911-1970)\end{array}$ & Zulay y Yonta & $\begin{array}{l}\text { Ópera en tres } \\
\text { actos }\end{array}$ & $i$ & $i$ \\
\hline $\begin{array}{lll}\text { Allen Torres } & \text { Castillo } \\
(1955) & & \end{array}$ & El delfín de Corobicí & Ópera & $\begin{array}{ll}\text { Allen } & \text { Torres } \\
\text { Castillo } & \end{array}$ & $i$ \\
\hline $\begin{array}{l}\text { Ismael Cardona } \\
\text { Valverde (1877-1969) }\end{array}$ & Amemos los árboles & $\begin{array}{l}\text { Comedia } \\
\text { musical } \\
\text { infantil }\end{array}$ & $i$ & 17 de mayo 1917 \\
\hline $\begin{array}{l}\text { Enmanuel García } \\
\text { Conejo (1872-1951) }\end{array}$ & Corobicí & $\begin{array}{l}\text { Dramatización } \\
\text { musical }\end{array}$ & $\begin{array}{ll}\text { Sor } & \text { Rosario } \\
\text { Quesada } & \text { Montes } \\
\text { de Oca (s.f.) }\end{array}$ & $\begin{array}{lr}\text { Setiembre } & 1938 \text { San } \\
\text { José, } & \text { Colegio } \\
\text { Superior } & \text { de } \\
\text { Señoritas } & \end{array}$ \\
\hline $\begin{array}{lll}\text { José Ángel } & \text { Coto } \\
\text { Avendaño (s.f.) } & \end{array}$ & Amor y mar & Cuento lírico & Rubén Torres (s.f.) & $\begin{array}{l}\text { Colegio Salesiano de } \\
\text { Cartago }\end{array}$ \\
\hline $\begin{array}{l}\text { José Rafael Araya } \\
\text { Rojas }(1890-1960)\end{array}$ & $\begin{array}{l}\text {-La feria de los niños } \\
\text {-Las flores y la } \\
\text { mariposa }\end{array}$ & $\begin{array}{l}\text { Obra escénica } \\
\text { infantil } \\
\text { Obra escénica } \\
\text { infantil }\end{array}$ & $\begin{array}{ll}\text { Luis } & \text { Dobles } \\
\text { Segreda } & \text { (1889- } \\
1956) & \end{array}$ & $\begin{array}{l}4 \text { de noviembre } 1943 \\
\text { Alajuela. Homenaje } \\
\text { al Presidente } \\
\text { Bernardo Soto } \\
\text { ¿ }\end{array}$ \\
\hline $\begin{array}{l}\text { José Daniel Zúñiga } \\
\text { Zeledón (1889-1981) }\end{array}$ & $\begin{array}{l}\text {-Los colores } \\
\text {-La cenicienta } \\
\text {-Los números } \\
\text {-Agua de lluvia } \\
\text {-La muñeca rota } \\
\text {-Labriegos y soldados }\end{array}$ & $\begin{array}{l}\text { Obras } \\
\text { escénico } \\
\text { infantiles }\end{array}$ & $i$ & $i$ \\
\hline Autor desconocido & El soldadito de plomo & $i$ & $i$ & $i$ \\
\hline
\end{tabular}

\section{(c) (i) (2)}

La Revista Estudios es editada por la Universidad de Costa Rica y se distribuye bajo una Licencia Creative Commons Atribución-NoComercial-CompartirIgual 3.0 Costa Rica. Para más información envíe un mensaje a 
Este recuento de obras musicales compuestas por autores nacionales nos muestra claramente la importancia que tuvo el género escénico-musical zarzuela, muy apreciado por los costarricenses desde 1850, cuando dieron inicio las representaciones teatrales en el Teatro Mora de San José.

\section{VI) CONCLUSIÓN}

Sin seguir estrictamente un criterio musicológico o técnico musical, este trabajo es más una recopilación de datos dispersos sobre los compositores nacionales que incursionaron en el campo de la zarzuela o de modestas obras escénicomusicales agrupadas como zarzuelas o como género chico, tan celebrado y gustado en España. Con lo anterior se quiso demostrar que en Costa Rica este género musical tuvo sus exponentes y que con muy buen tino dieron a los costarricenses lo mejor de su esfuerzo.

Considerada por muchos años como la primera zarzuela nacional "El marqués de Talamanca" (1900) (Gagini-Cuevas) es más que todo una zarzuela con ciertos ribetes históricos, al igual que "Toyupán" (1928) (Julio Mata) que tuvieron bastante éxito en la época de su estreno.

Si bien algunos consideran que "Los dos huérfanos" (1889) (Mateo Fournier) es la primera obra de carácter nacional, desconocemos tal afirmación por no existir rastro de su partitura original.

Las demás obras aquí reseñadas, en mayor o menor medida tuvieron un éxito relativo, fueron obras cuyas partituras desaparecieron o se conservan algunos fragmentos en archivo, por lo que es más que imposible conocerlas en su totalidad para emitir criterio, de ellas sólo quedan reseñas periodísticas o referencias en las biografías de sus autores.

\section{(C) $(0 \otimes)$}

La Revista Estudios es editada por la Universidad de Costa Rica y se distribuye bajo una Licencia Creative Commons Atribución-NoComercial-CompartirIgual 3.0 Costa Rica. Para más información envíe un mensaje a 
Revista Estudios, (39), 2019.

Diciembre 2019-Mayo 2020

ISSN 1659-3316

Le Franc Ureña Roberto

En la recopilación hecha se trató de seguir un orden cronológico de acuerdo a la

fecha de estreno de las diferentes obras, así como el lugar de su presentación, todo dentro de la escasa información existente.

Los datos presentados podrían servir como guía a futuras investigaciones más sistematizadas y con objetivos más claramente definidos, de momento consiste únicamente en un recuento y presentación de datos sobre algunos compositores nacionales y de sus obras en el campo denominado: ... LA ZARZUELA!

\section{NOTAS}

1.Ópera cómica o género lírico musical que surge en Francia en el siglo XVIII, de tono popular.

2. Composición dramática y musical alemana de tono folclórico y popular con texto dialogado alternado con canciones, coros y/o piezas musicales extensas.

3. Entrevista a Adrián Vega Villalobos, 16 de abril de 2017.

4. Ibidem

5. Ibidem

6. Conversación telefónica con don Wílber Alpírez Quesada en enero 2016.

\section{BIBLIOGRAFÍA}

Flores Zeller, Bernal (1978) La música en Costa Rica. San José, Costa Rica: Editorial Costa Rica.

Fumero Vargas, Patricia (1996) Teatro, público y Estado en San José, 1880-1914. San Pedro de Montes de Oca: Editorial de la Universidad de Costa Rica.

Le Franc Ureña, Roberto (2009) La familia Morales: Músicos por tradición. San Pedro de Montes de Oca: Editorial de la Universidad de Costa Rica.

\section{(c) (i) (2)}

La Revista Estudios es editada por la Universidad de Costa Rica y se distribuye bajo una Licencia Creative Commons Atribución-NoComercial-Compartirlgual 3.0 Costa Rica. Para más información envíe un mensaje a revistaestudios.eeg@ucr.ac.cr. 
Revista Estudios, (39), 2019.

Diciembre 2019-Mayo 2020

ISSN 1659-3316

Le Franc Ureña Roberto

Peña Goñi, Antonio (1967) España, desde la ópera a la zarzuela. Madrid, España: Alianza Editorial S.A.

Valencia, Antonio (1962) El género chico (Antología de textos completos). Madrid,

España: Editorial Taurus.

\section{OBRAS CONSULTADAS}

Cabezas, Esteban y Barquero, Zamira (2002). Catálogo de manuscritos e impresos del Archivo Histórico Musical Universidad de Costa Rica, Escuela de Artes Musicales: San Pedro de Montes de Oca.

Fumero, Patricia (1994) Base de datos: Las Compañías y las Representaciones teatrales en San José (1850-1915). Centro de Investigaciones Históricas Bibliográficas y Documentación N. 16. San Pedro de Montes de Oca: Universidad de Costa Rica.

Gagini, Carlos(1976) A través de mi vida. San José, Costa Rica: Editorial Costa Rica.

Monestel Arce, Yehudi(2012) La gran aventura musical de Alcides Prado. San José, Costa Rica: Lara Segura y Asociados.

Segura Chaves, Pompilio (2001) Desarrollo musical en Costa Rica durante el siglo XIX. Las bandas militares. Heredia, Costa Rica: Editorial Universidad Nacional.

Vargas Cullell, María Clara (2004) De las fanfarrias a las salas de concierto. Música en Costa Rica (1840-1940). San Pedro de Montes de Oca: Editorial Universidad de Costa Rica.

Varios (2011) Revista de Estudios N. 24. Sección de Historia y Cultura. Escuela de Estudios Generales. San Pedro de Montes de Oca: Editorial de la Universidad de Costa Rica.

\section{(c) (1)(2)}

La Revista Estudios es editada por la Universidad de Costa Rica y se distribuye bajo una Licencia Creative Commons Atribución-NoComercial-CompartirIgual 3.0 Costa Rica. Para más información envíe un mensaje a revistaestudios.eeg@ucr.ac.cr. 
Revista Estudios, (39), 2019.

Diciembre 2019-Mayo 2020

ISSN 1659-3316

\section{OTRAS FUENTES}

Archivo Teatro Nacional de Costa Rica. Álbumes históricos del Archivo Histórico del Teatro Nacional de Costa Rica

Archivo Histórico Musical, Escuela de Artes Musicales, Universidad de Costa Rica.

Documentos varios sobres la vida y obra de compositores nacionales.

\section{(c) (i) (2)}

La Revista Estudios es editada por la Universidad de Costa Rica y se distribuye bajo una Licencia Creative Commons Atribución-NoComercial-Compartirlgual 3.0 Costa Rica. Para más información envíe un mensaje a revistaestudios.eeg@ucr.ac.cr. 